research enterprise that the pressures to which it is exposed are already dangerous. The trick must be to encourage and even facilitate change in circumstances that are conducive to the opposite. The method must be to provide a host of different illustrations that change is not merely possible but likely to be beneficial. Taking an axe to some parts of bureaucracy would be a start. Too many people at present spend too much time on deliberations likely in the end to be pointless because there are no funds with which to back the outcome. The Natural Environment Research Council, its chairman's recent defence apart, seems a natural place to start. Simplifying the problem of managing expensive fixed facilities (telescopes, accelerators and the like) by wrapping them in a large bundle and putting them at the disposal of European scientists is another. Sweeping away the restrictive practices which at present ensure that large sums of money dedicated to graduate training are parcelled out to research supervisors, not to the young who will do the research, is a mistake that needs rectifying anyway, but whose remedy would change the rules of what has become a depressing game. There is, in other words, no shortage of things that might be done. But nothing will count for as much as the wit of the grant-making agency that is able to find an imaginative project, one already canvassed widely, and to back it to the hilt. The selectivity that everybody (the minister included) now asks for consists of being positive, not of finding new ways of saying no.

The House of Lords, being what it is, is also certain to take up the question of central administration. Four years ago, its own select committee tried to revive the appointment of a minister (part-time) with responsibility for science and technology, and was given a dusty answer by the present government. But the principles then apparent apply even in present circumstances. Although much of what is wrong with the academic research enterprise stems from faults within the system, it is also plain that the general coordination of publicly-supported research is inefficient. The Rothschild doctrine that government departments should become customers for research services through the agency of energetic chief scientists has long since collapsed under the reluctance of departments to spend money on any but problems that need solving by tomorrow. And defence research remains outside the system, and a law unto itself. The consequence is that the academic research enterprise is too isolated from the rest of what passes for research and, perhaps more important, that the British economy benefits much less than it should from what the government spends on all kinds of science. The government may not give the House of Lords its minister, but can it reasonably deny that there should be a mechanism for making better use of what is, after all, a lot of money?

\section{What price drugs?}

\section{New categories of drugs for which British patients must pay set dangerous precedents.}

WHEREVER there is health insurance, there are problems about the prices of modern pharmaceuticals. In most advanced societies, the cost of drugs exceeds 15 per cent of the cost of health services and, until recently, has also been a rising proportion in most places. That is why, throughout Europe, there have grown up elaborate systems by means of which governments attempt to control the cost of medication. The latest development is in Britain, where last week the minister responsible for the National Health Service, Mr Norman Fowler, announced a novel scheme for excluding from the services provided free by the health service two categories of medicines that are widely used - certain nonprescription medicines including aspirin but also some nearcosmetics which, it is suggested, people might in future prescribe for themselves and, second, tranquillizers and sleeping pills based on the diazepam structure which, the ministry has decided, are too often used as needless palliatives. Physicians will not of course be forbidden to prescribe these drugs, but patients will have to pay the full cost, not merely the standard fee for the servicing of a prescription by a pharmacist. There has been some grumbling on both counts, although that attaching to the first category of nonprescription drugs is insubstantial. The second class of drugs raises more interesting questions.

On the face of things, the obvious objection to discrimination between different categories of medicines is that it is an interference with medical practice. Schemes such as these, however, are used to control the cost of pharmaceuticals in both Sweden and France. The general principle seems to be that the drugs of chronic sickness or those required in serious illness or which are expensive should cost the patient nothing or very little, but the non-prescription medicines should be paid for as if, indeed, they were cosmetics. Elsewhere, in Switzerland as well as France, there are also approved lists of drugs that may be supplied within the terms of public health insurance, with a general understanding that approval will not be given to drugs that are notoriously less economical in use than others also on the market. Unsurprisingly, Switzerland is more permissive than France.

Nobody can reasonably complain at the British government's intention to exclude non-prescription drugs from the lists of those supplied free, although the saving may not be as great as expected when patients learn to persuade their physicians to prescribe more powerful (and more expensive) substitutes. The intended exclusion of the diazepams is more tricky because the category is so specific. The fact that the principal supplier of the drugs sold in Britain as Valium and Mogadon is the Swiss-based company Ciba-Geigy gives the decision a sense of political realism but may yet be a dangerous precedent. And while there seems ample evidence that the use of prescription tranquillizers is much more common than it should be, with some people as dependent on their pills as on their circadian clocks, what amounts to a decision that these relatively harmless materials should not be used for the treatment of recognizable conditions, while not a deliberate interference with the freedom of physicians, is a needless constraint on their way of working. A more generally drawn category of drugs qualifying for partial reimbursement would have been a wiser choice.

But why charge for drugs at all? That is the common complaint of the pharmaceutical manufacturers, who argue that attempts to regulate the cost of medicines can only reduce the pace of innovation and thus militate against the welfare of patients. The argument has some force, and is also accepted by most governments, which are unwilling to hazard the prosperity of their manufacturing industries. But most European governments also operate schemes for the regulation of the prices of drugs supplied within the public health services. In Britain, for example, the principle is that profits should be regulated in relation to the capital employed in research, development, manufacturing and marketing. What the pharmaceutical manufacturers do not acknowledge openly enough it that these arrangements are open to abuse. A manufacturer with a strongly-selling drug can set off against the income expenditure of the wildest kind - not merely the now well-publicized extravagances by which physicians are persuaded to prescribe particular drugs but also ill-conceived programmes of research and development. If the successful drug is one in great demand, and if there are no obvious competitors, the manufacturer has what was once described, in another context, as a licence to print money. Governments cannot equitably let such a state of affairs persist. The pharmaceutical industry, which is prone to howl whenever governments interfere, could usefully spend more of its energy trying to devise schemes for regulation which are equitable to both sides.

The issue is one on which the European Commission could usefully take a stand. Most community countries have public health insurance, either a national health service (sometimes called socialized medicine) as in Britain or compulsory private health insurance (which comes to the same thing) as in West Germany. Paying for non-prescription drugs is sensible, making chronic drugs free of charge is humane. Price regulation should not bear on specific drugs or on the industry as a whole, but on classes of drugs for the treatment of particular conditions which can be expected to proliferate with the passage of time. And prices should be uniform. 